\title{
A Cognitive Stylistic Approach to Humor in Norsemen: Mental Wellbeing in the Viking Age
} Manar El-Wahsh

Assistant Professor, Faculty of languages, October University for Modern Sciences and Arts (MSA), Egypt.

\begin{abstract}
Humor is rooted within being human. According to Nash (1985), humor is a fundamental trait of humanity, he goes on to equate it with "the power of speech, the mathematical gift, the gripping thumb, the ability to make tools," humor is a trait of being human (p. 1). Humor is examined in many fields, including psychology and linguistics (Attardo, 1994). This paper uses a cognitive stylistic approach to study humor by observing its building blocks or "narrative worlds" also known as "humorous worlds" (Marszalek, 2013). This study explores the humorous worlds in Norsemen, in which previous knowledge of the Vikings is required to unlock and grasp humor in this series. Norsemen is a Norwegian series that depicts the Vikings in a humorous manner showing them as men and women who are very skilled at raiding and killing but often failing at navigating their emotional and mental wellbeing. This study utilizes the premise that prior knowledge of culture, age, objects, characters, etc. has a great impact on understanding and appreciating humor. This paper argues that humor in Norsemen stems from an incongruity in these Norsemen's lives between pillaging and raiding on the one hand and mitigating issues of mental wellbeing and inclusion on the other. This incongruity tests our usual schema of the Vikings, and it refreshes this schema causing a humorous effect.
\end{abstract}

Keywords: cognitive stylistics, Norsemen, humorous worlds, schemata, disruption and repetition, incongruity 


\section{Introduction}

Humor is a phenomenon familiar to all humans across every culture. As a deeply rooted experience within the human consciousness, psychology takes interest in its motivations and manifestations. Humor is defined by Freud as "the ability to find similarity between dissimilar things - that is, hidden similarities" (Freud, 1990, p. 148). Psychology supplies many definitions of humor since it includes many facets. The definitions include "playful use of incongruity or alternative interpretations, a positive world view, a behavior that makes others smile, laugh, or lighten their mood, a physiological response, a social activity, a tool used to counter stressors" (Gibson, 2019, p. 1). Humor is also inspected in many other fields, including linguistics; "linguists have taken humor to be an all-encompassing category, covering any event or object that elicits laughter, amuses, or is felt to be funny" (Attardo, 1994, p. 4). Studies in humor have demonstrated they can offer prominent insights to the nature of human beings. "Although it is essentially a type of mental play involving a lighthearted, nonserious attitude toward ideas and events, humor serves a number of 'serious' social, emotional, and cognitive functions, making it a fascinating and rewarding topic of scientific investigation" (Martin, 2006, p. 1). This launches humor as a wide field of study, it is related "to anything that people say or do that is perceived as funny and tends to make others laugh, as well as the mental processes that go into both creating and perceiving such an amusing stimulus, and also the affective response involved in the enjoyment of it" (Martin, 2006, p. 5). This highlights the wide variety of situations that humor can examine fruitfully.

A major interest in "describing" the activities that create humor exists, as well as the "emotional response" people have as a result. Hence, rules have been established to "explain" humor, and to ultimately "predict" the incongruity that causes humor (Ruch, 2008, p. 17). In stylistic studies of humor, it is recognized that "humor requires an incongruity" (Simpson, 2004, p. 45). Incongruity deals with the cognitive aspect of humor, and it is concerned with "an intellectual reaction to something that is unexpected, illogical, or inappropriate in some other way." It includes "duality" and "contrast." Humans exist in an organized place; they have expectations of how things should be. Incongruity arise when "we experience something that doesn't fit into these patterns." (Morreall, 1983, p. 16). Absurdity is essential to provoke laughter, as laughter is "an affection arising from the sudden transformation of a strained expectation into nothing." This sudden change can cause amusement and laughter (Kant, 2005, p. 135).

This study uses Marszalek's $(2012,2013)$ model to examine humorous narratives in the series Norsemen. The framework is situated within cognitive stylistics and aims to scrutinize the role "narrative worlds" play in building humor. According to Marszalek, humorous worlds "enhance the humor of particular elements which appear in them by encouraging a playful interpretation of those elements" (Marszalek, 2013, p. 393). Norsemen is a Norwegian comedy series released in both Norwegian and English. The series is set in the village of Norheim in the year 790. "The comedy comes from the juxtaposition of their ancient, brutal struggle for survival and the minor concerns we all obsess over nowadays" (Raeside, 2017). The juxtaposition of such incongruous elements gives rise to many humorous worlds and authorizes an interpretation within a humorous mode.

\section{Humorous worlds}

Context is an integral, crucial aspect in linguistics. It "has to do with the fact that the grammatical system of a language has the overall function to serve human communication. And communication happens in certain contexts of utterance" (Meibauer, 2012, p. 9). Since humor is 
one of the manifestations of human interaction, context is essential in understanding and relating to humorous "narrative worlds" (Marszalek, 2013, p. 393). Narratives are "communicatively situated representations, making sense of them requires attending to how they are geared to particular communicative contexts" (Herman, 2009, p. 17). A narrative world that includes a humorous world is "context- dependent" and is best understood as a "part of the whole narrative world in which it belongs." This knowledge of context works to 'unlock' humorous potential, eventually causing the audience to accept a particular narrative world as humorous (Marszalek, 2016, p. 204). Narrative worlds, according to Gerrig (1993, p. 1), can move readers from their immediate reality and carry them to new worlds that include facts or fiction. He also proposes that two metaphors are used in relation to the creation of these worlds; a reader is either labeled as "being transported" by a narrative world or as "performing" this narrative world (Gerrig, 1993, p. 3). In humorous narrative worlds, humor triggers "humorous effects." In the process of making a humorous world or a humorous narrative, two types of humor appear: local and extended humor (Marszalek 2012, 2013).

\subsection{Local humor}

Local humor, a canned joke, or a narrative joke, is "inherently humorous regardless of the context in which they are found." Their humorous effect is restricted to the incidents that contain them. In other words, they are regarded as entertaining without the need to relate to a wider context. They are, as Marszalek describes them, "self-contained" (2013, p. 394). As a result, a canned joke does not rely on "contextual factors" and has little to do with the conversation at hand, and it is "quite interchangeable with respect to context" (Attardo, 2010, p. 296). Narrative jokes are "told by a narrator who often prefaces the joke with an announcement of the humorous nature of the forthcoming turn and who holds the floor through the telling and releases it for the reaction turn of the audience." It can also be "rehearsed" and "detached from the context in which they are told" (Attardo, 2001, pp. 61-62). The appreciation of a narrative joke depends on "our broad knowledge of the real world, rather than our knowledge of the particular narrative world of the text in which it occurs," as a result, this joke is inherently funny irrespective of the context (Marszalek, 2016, p. 204).

In Norsemen, canned jokes that are inherently funny without the need to refer to context take place many times. Chieftain Olav addresses health issues after being stabbed multiple times, saying "I can't help but complain." This phrase deviates from the usual phrase "can't complain." This contests the audience schema of the polite way to respond to someone's questions about health or conditions in general. His complaint is immediately humorous and does not need a wider context to be considered funny. Another incident of local humor manifests in a conversation between Arvid and Froya. Arvid and Froya are busy impaling their enemies' dead bodies, at the same time, Arvid craves food and seeks companionship to "grab a bite." Froya replies, "maybe we can defile first and then eat later? I mean, who likes to rape on a full stomach?" This is intrinsically amusing, as it is shocking to hear someone talks about appetite when they are about to raid, murder, maim, and rape people. The incongruity between socializing and grabbing a bite on the one hand, and rape and murder on the other is humorous regardless of context.

\subsection{Extended humor}

This type of humor is "non-local." Context is essential to evoke laughter and induce humor in extended humor. "Narratives often contain elements which are not funny out of context, as they are parts of a larger framework that can only be appreciated when the text is regarded as a whole." 
Marszalek names this structure: "humorous worlds," which is a narrative world devised to provoke a humorous response. Humorous worlds are built on "themes" and they run throughout the narrative, and this is the reason for calling them extended. Many humorous utterances are rendered non-humorous when they are taken out of context. "Their appreciation relies on our ability to look for humorous meanings beyond the short form to which they are constricted." Hence, this kind of humor is not "intrinsically humorous" like local humor. Humans make sense of the world, including understanding humor by referring to their previous knowledge of the world. This knowledge manifests itself here as knowledge of "narrative worlds". To understand this type of humor, a compiled stock of information about the world or context is essential. We need bits of information about the bigger picture to be able to find an incident of extended humor comical. Understanding contents allows the audience to unleash its humorous potential (Marszalek, 2013, p. 395). Ergo, taking this kind of joke "out of context" makes it unfunny; "as it is part of a larger framework that can only be appreciated when the text is regarded as a whole" (Marszalek, 2016, pp. 204-205). Marszalek builds on Emmott's concept "text-specific knowledge" in which readers use their prior knowledge and also renew this knowledge as they move forward in the text engagement (Emmott, 1997, p. 35).

In Norsemen, jokes about Varg (the main antagonist) include baldness. These jokes are not funny out of context because the context is very important in clarifying aspects of his character. Varg was a happy person married to a loving wife, and he also had a head full of hair. As he visits his best friend and later his biggest enemy Bjørn, he becomes the butt of a joke about his receding hairline, highlighting the fact that he is "thinning up top." This simple joke triggers a complete mental break down, causing Varg to snap and light the house on fire, killing everyone together with his own wife because of a comment about his hair. Norsemen's season 3 is mainly about Varg's baldness, attributing his evil, murder, rape, etc. to being bald. An image of a bald man is not necessarily intrinsically funny, but because the wider context allows the audience to compile all the jokes related to his baldness, they can appreciate the humor when he talks about his struggle with hair loss. The show's cues that accumulate adequate knowledge about Varg's past and deeds, help the audience to make sense of humor in this extended narrative. Every action relates to and is traceable to his baldness and its major effects on him, creating an extended line of humor.

\section{Disrupted elements}

Disrupted elements help significantly in constructing humorous worlds. They can shock the audience and trigger a humorous effect. Typically, they contest "stereotypical representations" of a certain situation (Marszalek, 2013, p. 369). Furthermore, worldmaking is a direct result of world disruption. The happenings in a narrative "introduce some sort of disruption or disequilibrium into a story world." This story world can be "actual or fictional, realistic or fantastic, remembered or dreamed" (Herman, 2009, p. 105). Humans draw on their prior knowledge to make sense of an ongoing interaction. They understand what is coming in relation to their existing knowledge of the concept at hand. This knowledge is represented as "packets of information". According to Marszalek, previous knowledge is useful to understand any type of discourse, however, it is particularly insightful to appreciate humor. While readers rely on incongruity between two concepts to understand a humorous text especially a canned joke, Marszalek argues that "such intrinsically amusing lines are not exceedingly common in humorous narrative fiction" (Marszalek, 2013, p. 396). 
Schema theory expands the "nature of narrative." Narratives have a natural composition, "consisting of strings of events." This theory offers insights to the structure and understanding of these events "providing extra information about what is unstated and also allowing further interpretation of what is stated" (Emmott, et al., 2014, p. 270). According to Marszalek, "humorous texts of any length are constructed from elements which manipulate the reader's general knowledge to introduce incongruity and achieve an amusing effect." Incongruity is essential to offer "humorous stimulus" as well as a surprised reaction in the audience. For readers to understand a text and its humorous effect, there is a need to activate schemata for certain "people," "objects," and "situations." The way in which schema gets disrupted is under examination here. This schema can be "deformed," "abnormal," or "exaggerated" (Marszalek, 2013, p. 397). Some schemata are clearly peculiar. "Our knowledge of the world can help us spot the abnormality" in a text. As sometimes, a certain schema may be stored in the human mind as "incongruous." According to Marszalek, several humorous worlds are constructed "from various types of disrupted elements, such as deformed objects and distorted characters" (p. 398). This schematic experience can change our response to a humorous world. "With their often unexpected, unusual choice and presentation of these elements, humorous worlds can be seen to 'disrupt' our stores of knowledge about the world" to encourage laughter (Marszalek, 2016, p. 210).

\subsection{Disrupted objects}

In a humorous text, objects do not have to be "inherently humorous" because "wider narrative context" navigates the audience's arrival at a humorous understanding. However, having these "unusual objects" adds humor to the text (Marszalek, 2013, p. 398). These "atypical props" can test our schemata causing a humorous effect (Marszalek, 2012, p. 46). In Norsemen, disrupted objects increase humor. As Viking warriors, Norsemen survive by raiding and pillaging; however, Rufus and Orm decide to melt down all their swords to make an abstract installation instead, "all the weapons are being melted into art." According to Rufus, "the installation is a very important focal point. It shows cultural strength." This of course presents a deformed schema of swords that is being melted to give way to an artistic installation, leaving the village defenseless against future, imminent attacks. There is also incongruity regarding the presence of the concept of installation in the year 700 while it is of course a modern concept. Also, on a deadly raid, Orm takes a pillow to make himself comfortable on the way there. This goes against the norm expected from a warrior, who instead of making sure his sword is in place, he drops it in the sea. He alternatively makes sure he has his pillow and has reserved a good seat for himself on the boat. This indicates that he is taking a trip rather than raiding a village.

Another disrupted object is arrows. In a peasants' revolt against Norheim, Arvid and the rest of the warriors are ambushed by angry peasants who do not want to be exploited or raided again. The peasants' revolt ends before it starts, as "they didn't exactly use live arrows. Just the fact that it didn't cross their minds that arrows need to be pointed." This contests the viewers' usual schema of arrows; they are sharp, pointed, and fatal objects. Moreover, a meeting between Varg and Orm contains many deviated objects. Orm finally gives Varg the long-coveted map, a map he has been searching for tirelessly, for which he killed and maimed many people. However, the map "looks like something a child could have drawn, so much trouble to get my hands on this map. And all I had to do was sail due west." The map is empty except for a childish drawing of a boat and a serpent. After the tension built up through two seasons of the series, the map finally appears, and it does not resemble a map with its intricacies at all. As Varg storms out, another disrupted object is displayed, which is his flag that is identical to the flag designed by the terrorist 
group ISIS. Instead of designing a flag that fits the time and the place, in Norsemen, the flag is simply ripped off the modern terrorist group's flag. This also causes incongruity between a familiar object (ISIS flag) and its misplacement in that time and place.

\section{2 Disrupted characters}

Characters have a significant capability in building humorous worlds. In a humorous text, characters can be "stereotypes" the audience can easily fathom. This stereotyping makes a certain notion equivalent to certain types of people, the audience will recall this notion's schema every time they encounter this character. "It can be suggested that a character stereotype will be formed through a series of social schemata disruptions, where social schemata refer to the knowledge we may have about particular people or social groups." Stereotypes of certain groups of people in extended humor is not uncommon. However, it requires characterization to set up a stereotype. Stereotyping makes characters effortlessly available (Marszalek, 2013, pp. 398-399).

Our usual understanding of the nature of the Viking's time is that they raided many parts of Europe, and their time was hard, which is a stereotypical idea that matches our schemata. However, Norsemen includes many schemata disruption and prototypical distortions of almost all characters occupying this time and space. The series starts with the chieftain Olav punching a slave in the face. Such brutality upsets him, and he later regrets punching the slave, saying "it's not really me, that fear-based leadership style stuff." The lexical choices are incongruous with their time, his character that raids and pillages would not worry about crossing the line and establishing a leadership style that he does not like. Another trait of Olav's is cleaning his sword because if a warrior does not clean his sword and brings it home to his wife, he "will hear about it." Warriors would not address a concern like the cleanliness of a sword or a wife's complaints about them. This causes schema disruption of both warriors and their swords.

Varg, who is the villain in the show, has many features that are relevant to the schema we have of a warrior. He is tough, ruthless, and resorts to killing, raiding, etc. to acquire money and status. However, Varg regards hair as the most important aspect of a man's personality. His assistant Hund spends a good part of the day brushing his mane, during such sessions, Varg expresses his beliefs about hair, "I cannot stress strong enough how important it is to have a luscious head of hair. My hair is my pride and my delight." Varg feels that he would be totally lost without his hair, "what will I be without it? A man's hair says everything about his personality. A bald man is like a blank rune stick. Zero content, no credibility. Men with a full head of hair simply have more options when it comes to cultivating their appearance." This explains a lot about the way he has been acting in previous episodes, as he was deprived of his hair by "male pattern baldness." Using the metaphor that compares a bald man to an empty rune stick disrupts our schema of such a supposedly tough warrior. They would be looking for survival during this tough time of the Vikings and not the appearance of their manes.

Additionally, Kark is a slave owned by the chieftain and his family. Unlike the usual nature of slaves, Kark is stoic and is very satisfied with being a slave. When asked about his lack of escapes attempts, he replies, "why would I run away? I'm here of my own free will. I was freed in the mid ' 80 s, I think. ' 86 . It just felt so wrong for me out there. I mean, everything goes so fast. It's just a totally different pace out there. I feel better in the strict confines here." He has been "institutionalized." Kark believes, "there's no better feeling than doing backbreaking work for someone else without pay." His interest, habits, and traits contest the usual schema of a slave, who 
would be miserable in enslavement and would welcome a chance to be emancipated. While any slave would welcome being freed, Kark repeatedly rejects offers to be freed.

As for Arvid, he is considered one of the most successful warriors in Olav's army. He believes that "raiding is pretty much our primary industry. We are Vikings, after all." He is always pillaging and in his free time, he goes on "mini-raids." However, his wife Liv interrupts his "business trip," as they have a "couple date" and that they must do something "social" together. The schema of the warrior who kills and mutates is disrupted and instead a new schema of a man afraid of his wife is created and refreshed. He leaves the raid and goes with his wife to a "poetry session."

As for Olav's brother, Orm, he contests the schema of a Viking on a bigger scale. On his way to a raid, Orm does not know how to get on board or hold his sword, eventually he drops it in the sea, "the sea giveth. And the sea taketh away. And this time the sea tooketh my sword." Upon arrival, instead of fighting, Orm falls into the sea and almost drowns. His wife saves him, but by the time he wakes up the raid is over and only one little girl is alive in the raided village. He tries to claim this victory and kill her, she beats him up instead. Furthermore, Orm does crochet and searches for yarn, he is repeatedly expressing that crocheting is his life. It is very hard to imagine a Viking warrior crocheting, this, of course, changes the usual schema and allows for the creation of a new one.

During a raid on Norheim, Varl asks his men to rape women on his behalf. Varl's men become reluctant to rape, "if my wife back home finds out that I'm raping people on my business trips, she's really gonna lose it." Unlike a Viking warrior who is expected to do just that in his trips, this solider is unhappy about these activities and fears his wife's reaction. He goes home to tell his wife about his trip, Varg "forced us way outside our comfort zone." His wife then advises him "to do something. You can't go on like this. Work is something you should look forward to, not something you should dread." This is not the schema we have for women in this age, who believe that work should be fulfilling. She advises her husband to talk to Varg about his feelings, "it's all about communication, right? What's the worst thing that can happen?" The normal outcome happens; Varg of course kills him. Another solider of Varg's is "afraid of heights," and is "terrified of small talk." These are modern social problems, and it is hard to imagine a man who kills for a living to be suffering these mental health issues.

\subsection{Disrupted situations and settings}

Normally, certain situations cause certain results. As humans, we expect a cause-and-effect relation between two incidents. "Situational humor plays on scripts, that is, knowledge of the sequences of actions in stereotypical situations" (Marszalek, 2012, p. 49). However, in humorous worlds, this is not always the case. Marszalek argues that settings can play a role in triggering humor "with a basic type of narrative world building block" (Marszalek, 2012, p. 44). One of the most disrupted situations in Norsemen takes place when Varg and Bjørn gather their armies to wage a war against one another. As both leaders agree to parley, not to end hostilities but to trashtalk, Hund feels he needs to stop to relieve himself, he is afraid he might "pee" his pants. An intense situation such as a war must be postponed because of Hund's urge to relieve himself. "You think it will take long? It was just that we were standing in front of the army, so I didn't get a chance to pee before we left. Now it's, uh... precarious. I guess I'll just do it in my pants. Then I don't have to worry about it anymore." This disrupts a situation of war as its leaders converse and deviates the schema to another entirely different situation. 
In the same war, Olav's army joins Varg's to defeat Bjørn, the two armies are not acquainted before the beginning of the war. Hund arrives to examine the site of the battle to find that his allies have been killing his army without knowing which side is the ally and which is the enemy. He starts by asking, "how do you know you aren't killing people from our side? It's not like we have the same uniforms." Certainly, Arvid does not know, "I don't know, I, uh... recognize our guys. I think." This seems farfetched for Hund, "you recognize 20,000 men? What about this? Did you just kill this guy? Because that's Gisle. A childhood buddy, one of the guys. We're a group of close-knit childhood friends who go on trips and...hang out on other occasions during the year." This is not a random case of deaths from friendly fire, it is the active killing of all men Arvid and his army could find, who happen to be their allies whom they had come to help win the war.

A disrupted schema takes place, when in the middle of impaling their victims, Arvid and Frøya discuss food, "are you feeling hungry? Do you think you'll be hungry again soon? Or do people think we should make something together later, or what? It's just that if people want to have dinner later, I guess I'll just grab something now. Because I feel I need a quick bite or something." This invitation for a "quick bite" is done during impalement. Frøya then apologizes for rejecting the invitation, "maybe we can defile first and then eat later? I mean, who likes to rape on a full stomach?"

These extracts show that disrupted elements are not inherently funny. The context plays a crucial role in deciphering the reason for these elements' amusing powers. Furthermore, "they do not need to involve an easily resolved incongruity between two contrasting concepts" (Marszalek, 2013 , p. 399). They create a "general kind of incongruity," a contrast between reality and texts "held is schemata" versus "diverging from schemata." Marszalek describes this disruption as "incongruous," "abnormal," and "abrasive". This "violation of schemata" achieves a humorous effect. Understanding humor is ongoing; the audience must always draw on their prior knowledge of the world to understand a humorous world. "The fact that distorted representations of entities still have the potential to be meaningful to us means that we must be able to actively assemble meanings rather than simply use the already existing schemata which we store in our minds." Furthermore, world-building elements can affect our interpretation and decision whether a world is humorous or not. "Once we perceive the world as humorous, we are likely to apply slightly different processing mechanisms when interpreting new incoming information" (Marszalek, 2013, p. 400). In Norsemen, many schemata are challenged and contested, which gives rise to humorous worlds. A shock is caused by many disruptions, this shock or surprise results from providing the audience with the opposite of their prior knowledge of the Vikings. Although many items and objects are normal, for instance pillows, crochet, swords, abstract installation, etc. yet they are disrupted here, as they can never exist in this context or time. This incongruity results in humor.

\section{Repetition and variation}

Under repetition and variation, a few world-building elements are grouped. These devices are linked to "patterns of identical or slightly altered elements which appear in the narrative world" (Marszalek, 2013, p. 402). To construct disrupted elements, "recurrence" is a method used for world-building. "Repetition, re- emergence or recurrence as tools for narrative humor creation are emphasized." This is used as a toolkit by authors to employ one humorous component and its "variants" repeatedly to cause laughter (Marszalek, 2016, p. 213). This serves as a way to invite 
humor and to "impress" the audience "by repeating the same joke over and over and magnifying its humorous effect each time" (Marszalek, 2012, p. 60).

Foregrounding creates "a shift of the stylistic level of the text from the usual background position to the foreground. In this way, everyday language can become defamiliarized." Foregrounding is established through deviance and parallelism. Deviance relates to creating an unconventional style of writing while parallelism is based on repetitive linguistic formations. However, in this model Marszalek substitutes parallelism with repetition and deviance with variation (Marszalek, 2012, p. 67).

Repetition is a "structural feature of comic narratives." Recurrence is considered essential in the creation of humorous worlds (Marszalek, 2013, p. 402). The same joke can be told many times and be received with humor every time. This repetition allows the audience to be more familiar with the joke, hence, they find it more amusing. Marszalek utilizes a Freudian concept; repetition is enjoyable because it makes the audience appreciate something recognizable and comfortable. "This rediscovery of what is familiar is pleasurable, and once more it is not difficult for us to recognize this pleasure as a pleasure in economy and to relate it to economy in psychical expenditure" (Freud, 1990, p. 148). Marszalek accounts for this humorous repetition as humor can pose itself as "a mental challenge which is only satisfying when it is difficult enough."

According to Marszalek, "local patterns are those which can be found in the extract itself - the reader does not need to have text-specific knowledge of the whole novel (up to the point when the passage appears) in order to see them." Some stylistic and syntactic patterns may appear many times. As a result, humorous components can occur. Marszalek categorizes these elements into "stylistic patterns related to the use of specific lexical and syntactic choices" and "some humorous elements which might potentially emerge from the extract as a result of this style of presentation" (2013, p. 404).

Local stylistic patterns can appear due to "a high proportion of the same words," and it can also manifest in repetition of "parallel sentence structures." The audience can easily pick on this heavy use of repetition. According to Marszalek, this is a way to achieve both foregrounding and create compelling characterization. "In a way that foregrounded literary language is made noticeable by drawing our attention to the style of the text" (2013, p. 405). In Norsemen, the phrase "can't help but complain" is repeated many times. Also, "a plan so crazy it might just work," was some advice from Arvid to Orm. This phrase was repeated many times by many characters in the series. The phrase "serious as cancer" also reoccurs many times. Furthermore, Orm usually addresses concerns with, "nine out of ten concerns are completely unfounded." Of course, pillaging and raping are a constant theme in the series. Slaves are usually referred to as "subhuman." Moreover, Orm repeatedly uses "heaven has got a new star" to refer to someone's death. Additionally, Arvid's overweight is ridiculed repeatedly in different ways, but the same meaning is intended. Rufus' cape is also a recurrent theme. After being enslaved, one of his greatest concerns is his cape's whereabouts, "I had a cape with me on the ship, I gave it to one of your colleagues who promised to return it." In another episode, Rufus "demands his cape back." The map, the crochet, Varg's flags are used repeatedly to evoke laughter. Furthermore, actors who are clearly in their 40s or 50s claim to be much younger and that the time of the Vikings has caused them to age prematurely, "just look at me. I'm 18 years old and I look like I'm well over 40." In separate occasions, the fear of an unfinished job arises. Varg gives his soldiers the order to kill someone, and they fail to do so completely. They just assume that they had finished their jobs, 
repeatedly, one of them asks the other "but what if he escapes while we're busy at the feast he comes back and seeks revenge later, or something like that?" This prediction comes true every time.

In Norsemen, deviation or variation takes place on a semantic level. In utterances like, "may he rest in shit," the choice of the deviant word shit here is incongruous with the usual use of the phrase. Furthermore, after Orm kills the Law speaker, he uses the metaphor journey to indicate that his life will soon be over, "this is where your journey ends." Also, Arvid's disrupts the saying "keep your friends close and your enemies closer," instead he says, "keep your friends close, and your enemies a little farther away." This indicates his lack of understanding and tactics when it comes to dealing with foes. Varg's replaces candy with raisin, "this will be like stealing raisins from a baby," and this also causes humor. The unlikely paradox of Orm's description of himself, "proud and humble." It is rare that these opposing adjectives are used to describe the same person. Also, deviation takes place when a parody of Trumps' campaign slogan make America great again is used repeatedly, "this map will make Vargnes great again!" The utterance causes humor since it uses both variation (deviation from a modern political campaign) and repetition.

Lexical deviation takes place as Varg uses the compound: the "old pretend-to-whisper-andsuddenly-spit-in-the-face trick," to describe a soldier's attempt to spit at him while pretending he just wants to talk. It also takes place when Orm forms the neologism excludors, by which he means people who always exclude him from social events. He also asks, "what does a slave speak? Slavonian? Or Slavish? Slavegian? Slavish, perhaps?" While some of these words are not formed by him, they are not normally used in this context. Historical deviation is the main type that makes an appearance in this series. Almost all jokes are funny because of their deviation from the Vikings age. Jokes like "wham, bam thank you ma'am," "color-blind," "inner voice," the joke is "script based", "we'll be like those twins that are connected from birth, that we haven't given a specific name yet," and "phantom pain" among many other jokes are amusing because they would not have been used in the time of the Vikings.

\section{Findings and conclusion}

This study focuses on the interpretation of a TV show through the lens of a humorous mode, which in turn encourages a humorous reaction. As mentioned earlier, this mode is created by disrupted elements, repetition, and variation. In humorous narratives, a humorous mode must be evoked to arrive at humor. The audience immerse themselves in such series without a serious intent, instead they use a lighthearted spirit to interpret it. This spirit offers us a temporary suspension of logical thinking and reasoning, in which we engage all the time. As clear in Norsemen, this humorous mode is achieved by connecting two unlikely, incongruous incentives. These different motivations can disrupt and contest our schemata and eventually refresh them. This creates a new schema that operates as a foundation on which the show is built.

The humorous worlds in Norsemen are only appreciated through a humorous mode, which is the ability to react in laughter and humor to the inaccuracies in the series. In Norsemen, the familiarity of our everyday modern life is used to interpret a different time, the Vikings age. The creators also combined another unlikely meld, which is our existing knowledge of the Vikings disrupted by this new knowledge that we must acquire to find this discourse humorous. The creators of the show did not only disrupt characters, objects, and situations, they did not only deviate from semantic, lexical, phonological, and historical norms, but they also deviated from an entire genre. The genre that depicts the Vikings as ruthless killing machines, is now tackling them 
as soft-hearted people who try to navigate their social and personal experiences to obtain mental wellbeing.

This unaccustomed way to look at the Vikings merged with the familiar way we look at our lives creates absurdity, causing a humorous effect. This, as this framework suggests, refreshes our schema and leaves us thinking whether people in the olden times had similar experiences to those we face nowadays. We do not usually believe they did, and if they did, we are sure they did not have the linguistic tools to express these fears, hopes, and concerns. So, this schematic disruption ultimately results in a schematic refreshment. Notions like rune sticks used in the same way we use paper or even mobiles to express thoughts or to ridicule someone is highly unusual schema. Also, ravens as technological advancement offers a modern take on ancient objects, which again evokes laughter. Also merging the intensity of the typical Viking warrior, who rapes and pillages, with a self-conscious warrior who is uncomfortable to rape is very unfamiliar and unlikely, hence, very amusing. It is interesting to see how the environment around the characters, which is depicted accurately, can include such highly unusual situations. This mix of the normal and the abnormal serves as a great medium for humor in Norsemen, creating many humorous worlds. This series, based on Freud's definition of humor, has found humor in merging similar, comfortable aspects with unfamiliar ones, our knowledge of the Vikings age and our personal knowledge of our everyday challenges of social life and mental health. 


\section{Data}

Helgaker, J. I. (Writer \& Director), Torgersen, J. (Writer \& Director). (October 2016). Norsemen [TV series]. In M. Arsky-Andersen, O. G, Iversen (Executive Producers), Norsemen. Netflix.

\section{References}

Attardo, S. (1994). Linguistic Theories of Humor. Walter de Gruyter.

Attardo, S. (2001). Humorous Texts: A Semantic and Pragmatic Analysis. Walter de Gruyter.

Attardo, S. (2010). Linguistic Theories of Humor. Walter de Gruyter.

Emmott, C. (1997). Narrative Comprehension: A Discourse Perspective. Oxford University Press.

Emmott, C., Alexander, M., \& Marszalek, A. (2014). Schema theory in stylistics. In M. Burke (Ed.), The Routledge Handbook of Stylistics (pp. 268-283). Routledge.

Freud, S. (1990). Jokes and Their Relation to the Unconscious (J. Strachey, Trans.; The Standard Edition). W. W. Norton \& Company.

Gerrig, R. (1993). Experiencing Narrative Worlds: On the Psychological Activities of Reading. Yale University Press. https://www.routledge.com/Experiencing-NarrativeWorlds/Gerrig/p/book/9780813336206

Gibson, J. (2019). An Introduction to the Psychology of Humor. Routledge.

Herman, D. (2009). Basic Elements of Narrative. John Wiley \& Sons.

Kant, I. (2005). Critique of Judgment (Bernard, Trans.). Barnes \& Noble Publishing.

Marszalek, A. (2012). Humorous worlds: A cognitive stylistic approach to the creation of humour in comic narratives [MPhil(R), University of Glasgow]. https://eleanor.lib.gla.ac.uk/record=b2979168

Marszalek, A. (2013). “It's not funny out of context!” In M. Dynel (Ed.), Topics in Humor Research (pp. 9-32.). John Benjamins Publishing Company. https://benjamins.com/catalog/thr.1.18mar

Marszalek, A. (2016). The humorous worlds of film comedy. In J. Gavins \& E. Lahey (Eds.), World Building: Discourse in the Mind. Bloomsbury Publishing.

Martin, R. (2006). The Psychology of Humor. Elsevier. https://www.elsevier.com/books/thepsychology-of-humor/martin/978-0-12-372564-6

Meibauer, J. (2012). What is a context? In R. Finkbeiner, J. Meibauer, \& P. B. Petra B. Schumacher (Eds.), What is a Context?: Linguistic approaches and challenges (pp. 393-422). Benjamins. https://benjamins.com/catalog/la.196.04mei

Morreall, J. (1983). Taking Laughter Seriously. SUNY Press.

Nash, W. (1985). The Language of Humour. Routledge. https:/www.routledge.com/TheLanguage-of-Humour/Nash/p/book/9780582291270 
Raeside, J. (2017, September 14). Norsemen review-Monty Python meets Game of Thrones in this Norwegian comedy | TV comedy | The Guardian. The Guardian. https://www.theguardian.com/tv-and-radio/2017/sep/14/norsemen-netflix-review

Ruch, W. (2008). Psychology of humor. In V. Raskin (Ed.), The Primer of Humor Research (Vol. 8, pp. 17-100). Walter de Gruyter.

Simpson, P. (2004). Stylistics: A Resource Book for Students. Routledge. 